\title{
PanAfrican Medical

\section{Health effects of agrochemicals among farm workers in commercial farms of Kwekwe district, Zimbabwe}

\author{
Regis Magauzi ${ }^{1}$, Bigboy Mabaera ${ }^{1}$, Simbarashe Rusakaniko', Anderson Chimusoro ${ }^{2}$, Nqobile Ndlovu', Mufuta Tshimanga ${ }^{1}$, Gerald \\ Shambira ${ }^{1}$, Addmore Chadambuka, ${ }^{1, \&}$, Notion Gombe ${ }^{1}$
}

${ }^{1}$ Dept of Community Medicine University of Zimbabwe, P.O. Box A178 Avondale, Harare, Zimbabwe, ${ }^{2}$ Provincial Medical Directorate, Midlands Province, P.O. Box 206, Gweru, Zimbabwe

${ }^{\&}$ Corresponding author: Addmore Chadambuka, Department of Community Medicine University of Zimbabwe, P.O. Box A178 Avondale, Harare, Zimbabwe

Key words: Organophosphates, cholinesterase activity, pesticide poisoning, agrochemicals, farm workers

Received: 11/05/2010 - Accepted: 07/07/2011 - Published: 11/07/2011

\begin{abstract}
Introduction: Farm workers are at a very high risk of occupational diseases due to exposure to pesticides resulting from inadequate education, training and safety systems. The farm worker spends a lot of time exposed to these harmful agrochemicals. Numerous acute cases with symptoms typical of agrochemical exposure were reported from the commercial farms. We assessed the health effects of agrochemicals in farm workers in commercial farms of Kwekwe District (Zimbabwe), in 2006. Methods: An analytical cross sectional study was conducted amongst a sample of 246 farm workers who handled agrochemicals when discharging their duties in the commercial farms. Plasma cholinesterase activity in blood specimens obtained from farm workers was measured using spectrophotometry to establish levels of poisoning by organophosphate and/or carbamates. Information on the knowledge, attitudes and practices of farm workers on agrochemicals use was collected using a pre-tested interviewer administered questionnaire. Bivariate and multivariate analyses were conducted to determine factors that were associated with abnormal cholinesterase activity. Results: The prevalence of organophosphate poisoning, indicated by cholinesterase activity of $75 \%$ or less, was $24.1 \%$. The median period of exposure to agrochemicals was 3 years $\left(Q_{1}:=1\right.$ year, $Q_{3}:=7$ years). Ninety eight $(41.5 \%)$ farm workers knew the triangle colour code for the most dangerous agrochemicals. Not being provided with personal protective equipment (OR 2.00; 95\% CI: $1.07-3.68)$ and lack of knowledge of the triangle colour code for most dangerous agro-chemicals (OR 2.02; $95 \%$ CI: $1.02-4.03$ ) were significantly associated with abnormal cholinesterase activity. Conclusion: There was organophosphate poisoning in the commercial farms. Factors that were significantly associated with the poisoning were lack of protective clothing and lack of knowledge of the triangle colour code for most dangerous agrochemicals. We recommended intensive health education and training of farm workers on the use of agrochemicals, provision of adequate and proper personal protective equipment as mitigation measures to this problem.
\end{abstract}

\section{Pan African Medical Journal. 2011 9:26}

This article is available online at: http://www.panafrican-med-journal.com/content/article/9/26/full/

(c) Regis Magauzi et al. The Pan African Medical Journal - ISSN 1937-8688. This is an Open Access article distributed under the terms of the Creative Commons Attribution License (http://creativecommons.org/licenses/by/2.0), which permits unrestricted use, distribution, and reproduction in any medium, provided the original work is properly cited.

Pan African Medical Journal - ISSN: 1937- 8688 (www.panafrican-med-journal.com)

Published in partnership with the African Field Epidemiology Network (AFENET). (www.afenet.net) 
Agriculture mortality rates have remained consistently high throughout the world in the last decade in contrast to other dangerous occupations [1]. Farm workers are at a very high risk of occupational diseases due to exposure to pesticides resulting from inadequate education, training and safety systems. In developed countries such as the US, farmers and farm workers comprise only $3 \%$ of the workforce, but they account for as much as $8 \%$ of all work-related accidents [2]. Developing countries are known to consume less than $20 \%$ of the world production of agrochemicals, which are responsible for as much as 1.1 million (70\%) of the total cases of acute poisoning in the working population [3].

Zimbabwe is one of the developing countries whose economy is mainly based on agriculture and in order to make foodstuffs of high quality and quantity, extensive use of agrochemicals is implemented [4]. In view of this, the pivot of production is the farm worker who spends a lot of time exposed to these harmful agrochemicals.

Agrochemicals are known to find their way in the blood systems of human beings through the mouth, nose, intact skin and the eyes. Several adverse health effects are known to result from exposure to pesticides including temporary acute effects like irritation of eyes and excessive salivation as well as chronic diseases like cancer, reproductive and developmental disorders. Effects on the Central Nervous System (CNS) like restlessness, loss of memory, convulsions and coma are also common. In addition, effects on parasympathetic and sympathetic nervous system have been widely reported including respiratory paralysis which is fatal [3].

More than $25 \%$ of the population of Zimbabwe is in commercial farming areas and with the current land reform programme, the figures are increasing. Although no official statistics regarding chemical poisoning have been reported in Zimbabwe, researchers have established through biological monitoring that prevalence due to agrochemical poisoning is as high as $30 \%$ [4]. With the current resettlement programme the figure is likely to be higher than before.

Kwekwe District is in the Midlands Province of Zimbabwe and has approximately 291 large and small scale commercial farms. The use of agrochemicals in these farms is rampant. The district repeatedly reported high incidence (26\%) of acute cases like excessive irritation, salivation, diarrhoea and fever which are typical symptoms that are associated with agrochemical exposure and were coming mainly from its commercial farming areas [5]. This study was conducted among farm workers in the commercial farms of Kwekwe District to establish the relationship between exposure to agrochemicals and diseases that were being reported in the district.

\section{Methods}

An analytical cross sectional study was conducted in Kwekwe District commercial farms among farm workers who handle agrochemicals when discharging their duties. Eleven farms were randomly selected using the lottery method from 30 farms in the southern part of the district. We excluded farms in the northern areas where indoor residual spraying for malaria control was conducted annually to avoid chemical poisoning due to malaria vector control.

For our sample size we assumed 95\% confidence level and expected prevalence of pesticide exposure (p) of 20\% [6] and absolute precision (d) of $5 \%$ using the formulae by Dobson [7]:

The required sample $n=z^{2} \times 246 \times\left(p \times(1-p) / d^{2}\right)$

Stratified sampling was conducted from one farm to the next until the required sample size was achieved. At each farm, farm workers whose duties involved contact with agrochemicals were categorized into the seven types of exposures that were identified namely, spraying, mixing, stores management, loading, repairing spraying equipment, working in recently sprayed areas and waste management of the agro-chemicals. A sampling fraction at each farm was calculated based on the numbers of farm workers in the types of exposures studied. This sampling method was conducted from one farm to the next until the required sample of 246 participants was achieved. These were then interviewed and $1 \mu l$ of blood samples was collected from those who consented to the required blood test.

Plasma cholinesterase activity in blood specimens obtained from farm workers was measured using spectrophotometry to establish levels of poisoning by organophosphate and/or carbamates. A mixture of blood, indicator (bromothymol blue) and acetylcholine perchlorate was prepared and allowed to stand for 10-15 minutes. The change in $\mathrm{pH}$ during this time period was measured by comparing the colour of the mixture with a set of permanent coloured glass standards contained in a disc. The change of $\mathrm{pH}$ was a measure of the level of cholinesterase activity in the blood. Harmful exposure to agrochemicals was defined as blood cholinesterase activity levels of $75 \%$ or less [8,9]. A blood sample drawn from the principal investigator (PI) and was tested for cholinesterase activity had $100 \%$ cholinesterase activity. This was used as the control result.

The design of the questionnaire was guided by the Health Belief Model (HBM) [10]. All the constructs except self efficacy were measured in this study. We pilot tested the questionnaire on 10 farm workers from a farm in another district in order to assess the flow of the questions and to what extent the questions collected the information we intended to. Information on knowledge, attitudes and practices of farm workers on agrochemicals use was collected using the pilot-tested interviewer administered questionnaire. We interviewed seven out of eleven farm owners and managers as key informants. The remainder was either not available on the day of visit or did not consent to the interview citing various reasons.

Ethical approval to conduct the research was obtained from Medical Research Council and permission from relevant government structures and farm owners. Confidentiality was assured to the participants and a signed informed consent form was used to prove that each participant had agreed to be interviewed and to have blood collected and tested. 
We analyzed the data using Epi Info 2002 to generate frequencies, Odds Ratios (OR), 95\% Confidence Intervals (CI) and p-values. Bivariate and multivariate analyses were conducted to determine factors that were associated with abnormal cholinesterase activity. Data from farm management were captured and analyzed by grouping together similar important points as well as noting some important contrasting information if there was any.

\section{Results}

\section{Socio Demographic Characteristics of Study Participants}

One hundred and forty nine $(60.6 \%)$ of the respondents were males and $97(39.4 \%)$ were females. The median age was 28 years $\left(Q_{1}=22\right.$ years, $\mathrm{Q}_{3}=37$ years). The median period of working with agrochemicals was 3 years $\left(\mathrm{Q}_{1}=1\right.$ years, $\mathrm{Q}_{3}=7$ years). More than half $(51.6 \%)$ of the respondents had at least attained secondary education. One hundred and fifty five (63\%) were married, 64 (26\%) were single and the remainder were either widowed or divorcees. Hundred (64.5\%) of the married respondents had their spouses working as farm workers at the same farm or another farm.

\section{Cholinesterase Activity Results}

Out of $241(98 \%)$ respondents who consented to blood test for cholinesterase activity, $58(24.1 \%)$ of them had abnormal cholinesterase activities of $75 \%$ or less. More females than males were affected although the difference was not statistically significant $(p=0.05)$. The most affected age group was the $21-30$ years with $24(41.4 \%)$ of the cases. Amongst the 58 farm workers with abnormal cholinesterase activity the most affected were sprayers (50\%), followed by those who worked in previously sprayed areas $49 \%$, loaders (31\%), mixers (29\%), repairers (22\%), waste disposers (9\%) and lastly stores managers (7\%).

\section{Knowledge, attitudes and practices of respondents towards the use of agrochemicals}

The respondents generally knew all possible routes of entry of agrochemicals into the human blood system. The routes of entry of agrochemicals were stated as nose (96\%), mouth (95\%), eyes (88\%) and skin $(83 \%)$.

One hundred and ninety eight (80.8\%) knew that triangle colour codes on agrochemical containers represent degree of toxicity of the agrochemicals. Ninety eight (41.5\%) knew that the most dangerous triangle colour code was purple. Those who did not know the meaning of any triangle colour code of agrochemical were more than 2 times (OR 2.03; 95\% CI: $1.02-4.03$ ) likely to have abnormal cholinesterase activity $(19.7 \%, \mathrm{n}=46)$ than those who were knowledgeable (Table 1).

Two hundred and eleven (85.8\%) of the respondents knew and agreed that they were at risk of agrochemical exposures. In addition, the respondents knew that personal protective equipment (PPE) could protect them from agrochemical exposure (95.5\%), periodic medical checks were beneficial $(98.4 \%)$, reporting ill health to management was beneficial $(91.1 \%)$ and that health education on agrochemicals was beneficial (97.6\%). The perceived barriers to avoiding agrochemical exposure were the unavailability of alternative jobs (75\%), management not adequately protecting workers (54\%), PPE not provided (29\%), fear by farm workers to report ill health to management (18\%) and PPE causing discomforts and therefore could not use them (15\%).

Twenty five (22.5\%) reported to management when they got ill, $44(39.6 \%)$ visited health facilities, 25 (22.5\%) did nothing, whilst 6 (5.4\%) treated themselves with drugs. The commonly implicated agrochemicals were Gramaxone 60 (36.6\%), Tamarone 40 (24.4\%), Monochrotophos 23 $(14.0 \%)$, Rogor 20 (12.2\%), Karate $20(12.2 \%)$ and Dimethoate $19(11.6 \%)$.

\section{Symptoms and their associations with abnormal cholinesterase activity}

One hundred and eleven (45.1\%) stated that they once suffered an illness that they knew or suspected to have been caused by agrochemicals. The five most common symptoms reported were headache $(66.7 \%)$, cold/flu $(62.2 \%)$, weakness $(45.9 \%)$, dizziness (41.1\%) and skin irritation (39.0\%). The study did not however establish any significant association between the different forms of symptoms and abnormal cholinesterase activity (Table 2).

\section{Provision of Personal Protective Equipment (PPE) and association with cholinesterase activity}

One hundred and seventy six (71\%) respondents were provided with at least one form of PPE. The commonest type of PPE provided was overalls $(65 \%)$, gumboots $(43 \%)$, gloves $(22 \%)$, face masks $(15 \%)$, hat $5 \%$ and goggles $(4 \%)$. More males than females $(130 / 149$ vs. $44 / 97)$ were provided with PPE. Not being provided with PPE was significantly associated with abnormal cholinesterase activity (OR 2.00; $95 \%$ CI: $1.07-3.68)$. In addition, being provided with a face mask was also found to be significantly associated with abnormal cholinesterase activity (OR 2.23 ; $95 \%$ CI: $1.04-4.80$ ) (Table 3).

\section{Frequencies of exposure to agrochemicals and their associations with abnormal cholinesterase activity}

The association of number of hours of exposure to agrochemicals with abnormal cholinesterase activity was explored using those who were working with agrochemicals for less than 2 hours as the reference population. It was established that working for more than 8 hours per day with agrochemicals was significantly associated with abnormal cholinesterase activity (OR 2.14; $95 \%$ CI: 1.17 - 3.90) (Table 4). 


\section{Independent risk factors for abnormal cholinesterase activity}

Logistic regression with the several variables under KAP, provision of PPE, health symptoms and frequency of exposure to agrochemicals based on the outcome of either having or not having abnormal cholinesterase activity was conducted using the step down regression approach and lack of knowledge on triangle colour codes and having no PPE emerged as the significant risk factors (Table 5) .

\section{Interviews with farm owners}

All the farm owners agreed that their farm workers were susceptible to agrochemical exposures. They all did not have workplace health and safety programs in place. The major precaution they highlighted was the provision of PPE to the farm workers and close supervision to ensure proper use of agrochemicals. Farm owners reported making sure that farm workers were not eating or smoking during handling of agrochemicals. In addition, they restricted workers who conduct spraying to the lowest number possible in circumstances where boom spraying was not possible. The farm workers did not undergo pre-employment and routine annual medical checks to ensure that they were fit for the job they were employed for and to obtain baseline data. Responsibility for the health and safety of the farm workers was on the farm owners themselves.

The farmers stated that there were no guidelines in use to cater for the welfare of the farm workers. They also reported that they were burning all chemical waste containers and made sure that all chemicals prepared for use each day were all used. Empty chemical containers were not allowed to be taken home by farm workers for their own use. This was put in place in order to avoid chemical poisoning in the homes of the farm workers.

The major challenges highlighted by the farmers were deaths related to absenteeism from illnesses like headache, abdominal pains, weakness and the like. The nearby clinic was reported having inadequate stocks of drugs to treat diseases that most farm workers were suffering from.

\section{Discussion}

The study revealed that the prevalence of abnormal cholinesterase activity due to agrochemical poisoning amongst the farm workers was $24.1 \%$. The farm workers were exposed to unacceptably high levels of pesticides (i.e. those levels that cause abnormal cholinesterase activity AchE $\leq 75 \%$ ). The result is consistent with previous studies conducted in Zimbabwe before the resettlement program [6,11-13]. The findings indicate that health and safety programmes in the commercial farms in Zimbabwe are inadequate. Other studies conducted in Ethiopia have also shown that handling and storage of chemical pesticides, personal hygiene and the proper use of personal protective equipment by farm workers was below a standard $[14,15]$ and in the Philippines poor personal hygiene and experiencing spills on farm workers bodies were risk factors [16,17].

This study also established that provision of PPE to the farm workers was lacking and where it was provided, it was inadequate. Although this study did not include the issues of appropriateness and proper usage of the PPE we cannot rule out this to be an aggravating factor. Being provided with face masks was found to be a significant risk factor. This might mean the type of PPE was either inappropriate or was not being used properly. The face masks were possibly concentrating the agrochemicals close to the nasal areas increasing risk of poisoning through inhalation or they were not being used at all because they were perceived as a hindrance to smooth air flow by the farm workers.

This study also revealed that males were less likely to have abnormal cholinesterase activity compared to females although this was not statistically significant. We established that women were mainly working in areas that would have been sprayed previously without any PPE and indirectly came into contact with residual or suspended aerosols of pesticide. Lu showed that those who re-entered recently sprayed areas had higher risk of poisoning than those who did not [16]. On the other hand more males were involved in mixing, spraying, repairing of equipment or managing the stores for pesticides where there was direct contact with pesticides and PPE provision was prioritized. Hence, males were more likely to be provided with PPE than females. This differences in the areas of work between males and females and subsequently differences in prioritization of PPE provision could be a possible explanation for the differences in cholinesterase activity between males and females.

More than $80 \%$ of our participants knew the routes of entry of pesticides in the human body and the triangle colour coding. They even knew the pesticides that were responsible for their poisoning. Contrary to this, a study in Tanzania established that majority of farm workers knew that pesticides could enter the human body and showed awareness of potential health hazards of the different pesticides used in their service areas but they did not recognize what pesticides were responsible for the poisonings [18].

However, not knowing the triangle colour code for the most dangerous agrochemicals (purple triangle) was significantly associated with abnormal cholinesterase activity. The workers may not have taken precautionary measures when handling agrochemicals due to ignorance resulting in high exposures that affected their cholinesterase activity. Other studies have shown that the preventive measures that were taken by farm workers were low, and the lower their knowledge was, the lower were the preventive measures applied [19].

Forty five percent of the participants stated that they had suffered some multiple symptoms at one point in time that they knew or suspected to have been caused by pesticide exposure. Salameh et al also established that agricultural workers have a higher prevalence of multiple symptoms, which may be due to sub-acute intoxications by pesticides that did not need hospitalization. In addition, the workers had a higher risk of having an acute intoxication due to pesticides thereby exposing them to life-threatening situations [15].

Working for more than 8 hrs per day was significantly associated with abnormal cholinesterase activity. It is expected that working more than the stipulated number of hours per day can be strenuous and fatigue cripples in thereby reducing compliance to the stipulated precautionary measures. 
Spray men were affected more by chemical exposure followed by those who were working in sprayed areas. The repairers and waste disposers were the least affected. Unlike other studies, none of the types of exposures studied here was significantly associated with cholinesterase activity $[6,13]$. Although we could not establish after how long workers were allowed to work in the sprayed areas, this could be an important area to reckon.

Some limitations in our study were that we did not have time to look at the process of handling agrochemicals from stores to disposal due to time and resource constraints and we relied on the self reported information. Recall bias cannot be ruled out.

\section{Conclusion}

The prevalence of abnormal cholinesterase activity among the farm workers due to chemical poisoning was high. The major exposures were spraying and working in the sprayed areas. Ignorance of the colour codes for the dangerous agrochemicals, working for more than 8 hours per day, not being provided with PPE and being provided with face masks were significantly associated with abnormal cholinesterase activity. Intensification of health education and trainings on agrochemicals handling and use, reduction of number of working hours to normal 8 hours or less, provision of adequate and proper PPE and periodic medical checks for farm workers were recommended from the findings of the study.

\section{Competing interests}

The authors declare no competing interests.

\section{Acknowledgements}

We would like to acknowledge Mr. Wilbert Murambiwa of the Pharmacology Department for providing spectrophotometry services and Professor Charles FB Nhachi for providing literature on the pharmacology of agrochemicals.

\section{Authors' Contributions}

RM, BM, SR, AC, NN, AC, NG: conception of the problem, design, collection, analysis and interpretation of data and drafting and critical review of the final article. MT, GS: oversight of all the stages of the research, critical reviewed the final draft for academic content. All the authors have read and approved the final version of the manuscript.

\section{Tables}

Table 1: Knowledge, attitude and practices of respondents and their associations with abnormal blood test for cholinesterase activity, Kwekwe District

(Zimbabwe),

2006

Table 2: Symptoms experienced by farm workers and their associations with abnormal blood test for cholinesterase activity, Kwekwe District (Zimbabwe),

Table 3: Personal protective equipment (PPE) provision to farmers and associations with abnormal blood test for cholinesterase activity, Kwekwe district

(Zimbabwe),

Table 4: Duration of exposure to agrochemicals for farm workers interviewed in Kwekwe District (Zimbabwe) and their associations with abnormal blood test for cholinesterase 2006

Table 5: Independent risk factors for abnormal blood test cholinesterase activity among farm workers, Kwekwe District (Zimbabwe), 2006

\section{References}

1. International Labour Organization. /97/23, (1197 Press release) ILO warns on farm safety; Agriculture mortality rates remain high; Pesticides pose major health risks to global workforce Press release. 22 October 1997. http://www.ilo.org/global/about-the-ilo/pressand-media-centre/press-releases/WCMS_008027/lang--en/index.htm. Accessed on 19 June 2011

2. Médecins Sans Frontières (MSF). Chemicals risk assessment and management. http://www.doctorswithoutborders.org/news/2005/07-252005.cfm. Accessed on 30 June 2006

3. United States Environmental Protection Agency (US EPA). Organophosphate pesticide information: overview of malathion risk assessment 2000. http://www.epa.gov/pesticides/op/malathion.htm. Accessed on 25 July 2005 
4. National Social Security Authority of Zimbabwe. A case study on the effects on workers and the environment of agrochemicals used in tea plantations in the Eastern Highlands of Zimbabwe. Occupational Health News. 2002; 52-53

5. Ministry of Health and Child Welfare, Kwekwe District Hospital. Inpatient Quarterly Returns for 2005

6. Bwititi TB, Chikuni O, Loewefon R, Murambiwa W, Nhachi C, Nyazema N. Health hazards in organophosphates use among farm workers in large scale farming sector. Central African Journal of Medicine. 1987; 33(5): 120-126. This article on PubMed

7. O'Donnell MP. Health promotion in the workplace. 2001; 138. John Wiley \& Sons Inc (Feb 1 1984)

8. Limperos G and Ranta KE. A rapid screening test for the determination of the approximate cholinesterase activity of human blood. Science. 1953 Apr 24;117(3043):453-5. This article on PubMed

9. Edson EF. Treatment of organophosphorus poisoning. Br Med J. 1959 Jun 6;1(5135):1476. This article on PubMed

10. Sheeran P, Abraham C. The health belief model: Conner M, Norman P. eds. Predicting health behaviour. Buckingham: Open University Press. $2001 ; 23-61$

11. Nhachi CFB. A study of organophosphate poisoning cases at one rural and one urban hospital. Central African Journal of Medicine. 1988; 34: 180-185. This article on PubMed

12. 12. Mabaera B, Matchaba RB, Laver S, Tshimanga M, and Mudyiradima R. Problems associated with the use of pesticides in coffee plantations in the Eastern highlands of Zimbabwe. 2000; 12: 29-36

13. Nhachi CFB and Kasilo OMJ. Pesticides in Zimbabwe, toxicity and health implications. 1996. University of Zimbabwe Publications (UZP)

14. Makonnen $\mathrm{Y}$ and Ejigu D. Plasma cholinesterase level of Ethiopian farm workers exposed to chemical pesticide 2002. Occup Med (Lond). 2005; 55(6):504-5. This article on PubMed

15. Salameh PR and Abi Selah B. Symptoms and acute pesticide intoxication among agriculture workers in Lebanon, J. Med Liban. 2004 AprJun;52(2):64-70. This article on PubMed

16. Lu JL. Risk factors to pesticide exposure and associated health symptoms among cut-flower farmers. Int J Environ Health Res. 2005 Jun;15(3):161-9. This article on PubMed

17. Del Prado-Lu JL. Pesticide exposure, risk factors and health problems among cutflower farmers: a cross sectional study. J Occup Med Toxicol. 2007 Sep 18;2:9. This article on PubMed

18. Nqowi AV, Maeda DN and Partanen TJ. Knowledge, attitudes and practices (KAP) among agricultural extension workers concerning the reduction of the adverse impact of pesticides in agricultural areas in Tanzania. Med Lav. 2002; 93 (4): 338-46. This article on PubMed

19. Salameh PR, Baldi I, Brochard P and Saleh BA. Pesticides in Lebanon: a knowledge, attitude, and practice study. Environ Res. 2004 Jan;94(1):1-6. This article on PubMed 
Table 1: Knowledge, attitude and practices of respondents and their associations with abnormal blood test for cholinesterase activity, Kwekwe District (Zimbabwe), 2006

\begin{tabular}{|c|c|c|c|c|c|}
\hline Variable & & $\begin{array}{c}\text { Cholinesterase activity } \leq \\
75 \% \\
(\mathrm{~N}=58)\end{array}$ & $\begin{array}{c}\text { Cholinesterase } \\
\text { activity }>75 \% \\
(\mathrm{~N}=183)\end{array}$ & Odd ratio $(95 \% \mathrm{CI})$ & p-value \\
\hline Don't know colour code & $\begin{array}{l}\text { Yes } \\
\text { No }\end{array}$ & $\begin{array}{l}17 \\
41\end{array}$ & $\begin{array}{c}31 \\
152\end{array}$ & $2.03(1.02-4.03)$ & 0.04 \\
\hline Agrochemicals dangerous to health & $\begin{array}{l}\text { Yes } \\
\text { No }\end{array}$ & $\begin{array}{c}54 \\
4\end{array}$ & $\begin{array}{c}164 \\
19\end{array}$ & $1.56(0.51-4.80)$ & 0.31 \\
\hline $\begin{array}{l}\text { One's duty risky due to agrochemical } \\
\text { exposure }\end{array}$ & $\begin{array}{l}\text { Yes } \\
\text { No }\end{array}$ & $\begin{array}{c}52 \\
6\end{array}$ & $\begin{array}{c}160 \\
23\end{array}$ & $1.25(0.48-3.23)$ & 0.65 \\
\hline $\begin{array}{l}\text { PPE protects from agrochemical } \\
\text { poisoning }\end{array}$ & $\begin{array}{l}\text { Yes } \\
\text { No }\end{array}$ & $\begin{array}{c}57 \\
1\end{array}$ & $\begin{array}{c}173 \\
10\end{array}$ & $3.29(0.41-26.30)$ & 0.21 \\
\hline PPE causes discomfort & $\begin{array}{l}\text { Yes } \\
\text { No }\end{array}$ & $\begin{array}{l}10 \\
48\end{array}$ & $\begin{array}{c}26 \\
157\end{array}$ & $1.26(0.56-2.79)$ & 0.57 \\
\hline $\begin{array}{l}\text { Always uses PPE when handling } \\
\text { agrochemicals }\end{array}$ & $\begin{array}{l}\text { Yes } \\
\text { No }\end{array}$ & $\begin{array}{l}31 \\
27\end{array}$ & $\begin{array}{l}98 \\
85\end{array}$ & $1.00(0.55-1.80)$ & 0.99 \\
\hline Seldom uses PPE to protect oneself & $\begin{array}{l}\text { Yes } \\
\text { No }\end{array}$ & $\begin{array}{l}14 \\
44\end{array}$ & $\begin{array}{c}28 \\
155\end{array}$ & $1.76(0.85-3.63)$ & 0.12 \\
\hline
\end{tabular}

Table 2: Symptoms experienced by farm workers and their associations with abnormal blood test for cholinesterase activity, Kwekwe District (Zimbabwe), 2006

\begin{tabular}{|c|c|c|c|c|c|}
\hline Symptom experienced & & $\begin{array}{c}\text { Cholinesterase activity } \leq \\
75 \% \\
(\mathrm{~N}=58)\end{array}$ & $\begin{array}{c}\text { Cholinesterase activity } \\
>75 \% \\
(\mathrm{~N}=183)\end{array}$ & Odd ratio $(95 \% \mathrm{CI})$ & p-value \\
\hline Headache & $\begin{array}{l}\text { Yes } \\
\text { No }\end{array}$ & $\begin{array}{l}43 \\
15\end{array}$ & $\begin{array}{c}120 \\
63\end{array}$ & $1.51(0.78-2.92)$ & 0.22 \\
\hline Cold/flu & $\begin{array}{l}\text { Yes } \\
\text { No }\end{array}$ & $\begin{array}{l}39 \\
19\end{array}$ & $\begin{array}{c}114 \\
69\end{array}$ & $1.24(0.67-2.32)$ & 0.50 \\
\hline Weakness & $\begin{array}{l}\text { Yes } \\
\text { No }\end{array}$ & $\begin{array}{l}25 \\
33\end{array}$ & $\begin{array}{l}87 \\
96\end{array}$ & $0.84(0.46-1.52)$ & 0.56 \\
\hline Dizziness & $\begin{array}{l}\text { Yes } \\
\text { No }\end{array}$ & $\begin{array}{l}25 \\
33\end{array}$ & $\begin{array}{c}76 \\
107\end{array}$ & $1.07(0.59-1.94)$ & 0.83 \\
\hline Skin irritation & $\begin{array}{l}\text { Yes } \\
\text { No }\end{array}$ & $\begin{array}{l}22 \\
36\end{array}$ & $\begin{array}{c}72 \\
111\end{array}$ & $0.94(0.51-1.73)$ & 0.85 \\
\hline Sore eyes & $\begin{array}{l}\text { Yes } \\
\text { No }\end{array}$ & $\begin{array}{l}25 \\
33\end{array}$ & $\begin{array}{c}71 \\
112\end{array}$ & $1.20(0.66-2.17)$ & 0.56 \\
\hline Nausea & $\begin{array}{l}\text { Yes } \\
\text { No }\end{array}$ & $\begin{array}{l}21 \\
37\end{array}$ & $\begin{array}{c}73 \\
110\end{array}$ & $0.86(0.46-1.58)$ & 0.62 \\
\hline Abdominal pains & $\begin{array}{l}\text { Yes } \\
\text { No }\end{array}$ & $\begin{array}{l}14 \\
39\end{array}$ & $\begin{array}{c}47 \\
136\end{array}$ & $1.41(0.74-2.79)$ & 0.29 \\
\hline Fever & $\begin{array}{l}\text { Yes } \\
\text { No }\end{array}$ & $\begin{array}{l}17 \\
41\end{array}$ & $\begin{array}{c}41 \\
142\end{array}$ & $1.44(0.74-2.79)$ & 0.28 \\
\hline Blurred vision & $\begin{array}{l}\text { Yes } \\
\text { No }\end{array}$ & $\begin{array}{l}19 \\
39\end{array}$ & $\begin{array}{c}38 \\
145\end{array}$ & $1.86(0.92-3.75)$ & 0.06 \\
\hline
\end{tabular}


Table 3: Personal protective equipment (PPE) provision to farmers and associations with abnormal blood test for cholinesterase activity, Kwekwe district (Zimbabwe), 2006

\begin{tabular}{|c|c|c|c|c|c|}
\hline Type of PPE & & $\begin{array}{c}\text { Cholinesterase activity } \leq \\
75 \% \\
(\mathrm{~N}=58)\end{array}$ & $\begin{array}{c}\text { Cholinesterase activity > } \\
75 \% \\
(\mathrm{~N}=183)\end{array}$ & $\begin{array}{l}\text { Odd ratio } \\
(95 \% \mathrm{CI})\end{array}$ & p-value \\
\hline \multirow{2}{*}{ Gum shoes } & Yes & 22 & 81 & \multirow{2}{*}{$0.77(0.42-1.41)$} & \multirow{2}{*}{0.40} \\
\hline & No & 36 & 102 & & \\
\hline \multirow{2}{*}{ Overalls } & Yes & 32 & 124 & \multirow{2}{*}{$0.59(0.32-1.07)$} & \multirow{2}{*}{0.08} \\
\hline & No & 26 & 59 & & \\
\hline \multirow{2}{*}{ Face masks } & Yes & 13 & 21 & \multirow{2}{*}{$2.23(1.04-4.80)$} & \multirow{2}{*}{0.04} \\
\hline & No & 45 & 162 & & \\
\hline \multirow{2}{*}{ Gloves } & Yes & 12 & 38 & \multirow{2}{*}{$1.00(0.48-2.06)$} & \multirow{2}{*}{0.99} \\
\hline & No & 46 & 145 & & \\
\hline \multirow{2}{*}{ Hats } & Yes & 2 & 10 & \multirow{2}{*}{$0.61(0.13-2.90)$} & \multirow{2}{*}{0.42} \\
\hline & No & 56 & 173 & & \\
\hline \multirow{2}{*}{ Goggles } & Yes & 2 & 8 & \multirow{2}{*}{$0.78(0.16-3.78)$} & \multirow{2}{*}{0.55} \\
\hline & No & 56 & 175 & & \\
\hline \multirow{2}{*}{ PPE not provided } & Yes & 24 & 48 & \multirow{2}{*}{$2.00(1.07-3.68)$} & \multirow{2}{*}{0.03} \\
\hline & No & 34 & 135 & & \\
\hline
\end{tabular}

Table 4: Duration of exposure to agrochemicals for farm workers interviewed in Kwekwe District (Zimbabwe) and their associations with abnormal blood test for cholinesterase activity 2006

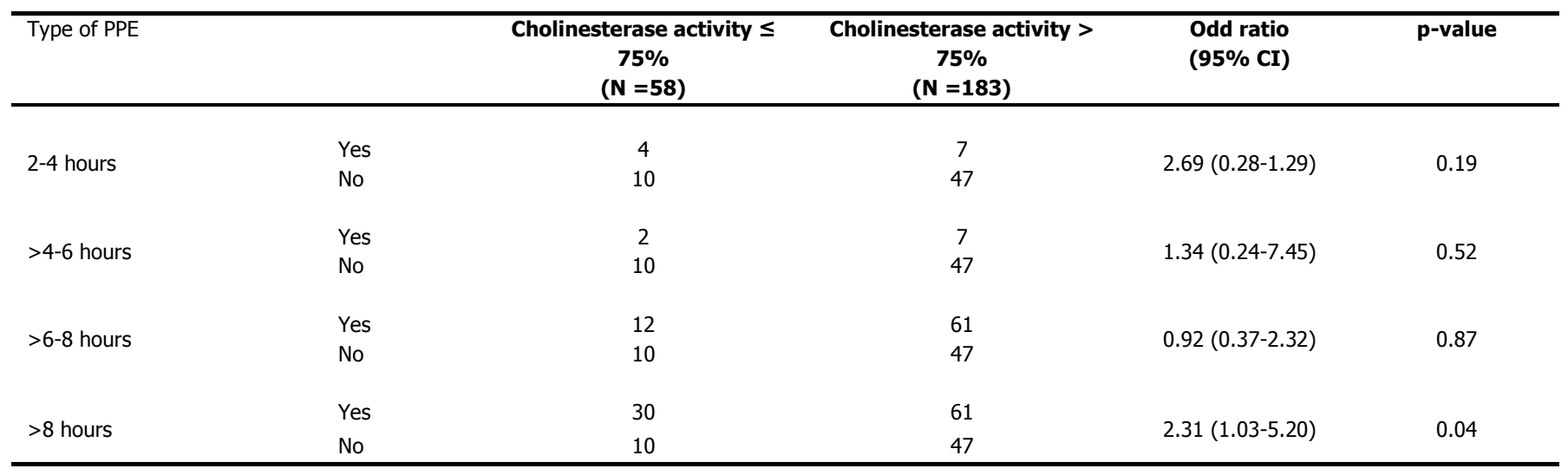

Table 5: Independent risk factors for abnormal blood test cholinesterase activity among farm workers, Kwekwe District (Zimbabwe), 2006

\begin{tabular}{|c|c|c|c|c|c|}
\hline Abnormal cholinesterase activity & & $\begin{array}{c}\text { Cholinesterase activity } \leq \\
75 \% \\
(\mathrm{~N}=58)\end{array}$ & $\begin{array}{c}\text { Cholinesterase activity } \\
>75 \% \\
(\mathrm{~N}=183)\end{array}$ & $\begin{array}{l}\text { Odd ratio } \\
(95 \% \mathrm{CI})\end{array}$ & p-value \\
\hline Don't know triangle colour codes & $\begin{array}{l}\text { Yes } \\
\text { No }\end{array}$ & $\begin{array}{l}17 \\
41\end{array}$ & $\begin{array}{c}31 \\
152\end{array}$ & $2.41(1.13-2.28)$ & 0.02 \\
\hline Having a face mask & $\begin{array}{l}\text { Yes } \\
\text { No }\end{array}$ & $\begin{array}{l}13 \\
45\end{array}$ & $\begin{array}{c}21 \\
162\end{array}$ & $0.69(0.23-2.18)$ & 0.52 \\
\hline Having no PPE & $\begin{array}{l}\text { Yes } \\
\text { No }\end{array}$ & $\begin{array}{l}24 \\
34\end{array}$ & $\begin{array}{c}48 \\
135\end{array}$ & $2.11(1.11-3.99)$ & 0.05 \\
\hline
\end{tabular}

